\title{
Comparison of Some Numerical Approaches for Determination of Dynamic Characteristics in Beam and Plate Elements
}

\author{
Mustafa Tolga Yavuz ${ }^{1 *}$, Ibrahim Ozkol ${ }^{2}$ \\ 1* *Istanbul Technical University, Department of Aeronautical Engineering, İstanbul, Turkey, (ORCID: 0000-0001-7728-3713), yavuzmusta@itu.edu.tr \\ 2 Istanbul Technical University, Department of Aeronautical Engineering, İstanbul, Turkey, (ORCID: 0000-0002-9300-9092), ozkol@itu.edu.tr
}

(1st International Conference on Applied Engineering and Natural Sciences ICAENS 2021, November 1-3, 2021)

(DOI: $10.31590 /$ ejosat.1011242)

ATIF/REFERENCE: Yavuz, M. T., Ozkol, I. (2021). Comparison of Some Numerical Approaches for Determination of Dynamic Characteristics in Beam and Plate Elements. European Journal of Science and Technology, (28), 1454-1468.

\begin{abstract}
In the last few decades, many numerical methods have been developed and employed to solve for various types of linear and nonlinear equations due to challenges in the aspect of the implementation of governing equations and boundary conditions, computation time, algorithm complexity, accuracy, convergency, stability of the solution and so on. Of the numerical methods in the open literature, differential quadrature (DQM), differential transform (DTM), and finite difference (FDM) methods are expressed briefly with their algorithms and compared to each other for the modal analysis of beam and plate elements. For simplicity, shear strains effects are neglected for the chosen structural elements, and plate element is reduced to one-dimensional case up to chosen simply-supported boundary condition. Under these assumptions, computed non-dimensional natural frequencies by applying concerned methods are tabulated, and mode shapes are plotted. To understand the strength and accuracy of employed methods, numerical results in the high vibration modes are investigated, and it is seen that DTM gives faster and more accurate solutions while the results of DQM depend on chosen grid distribution and has less accurate than DTM. However, the ease of implementation and accurate results for multidimensional cases are pros properties of the DQM.
\end{abstract}

Keywords: Dynamic Characteristics, Differential Quadrature, Differential Transform, Euler Beam, Finite Difference, Kirchhoff Plate.

\section{Kiriş ve Plak Elemanlarda Dinamik Karakteristiklerin Belirlenmesi için Kullanılan Bazı Sayısal Yaklaşımların Karşılaştırılması}

$\ddot{O} \mathbf{z}$

Son yıllarda, temel denklemlerin ve sınır koşullarının kodlanması, hesaplama süresi ve algoritma karmaşıklığı azaltmak, çözümün doğruluğunu artırmak ve hızlı yakınsamasını sağlamak, çözümün kararlılığı artırmak vb. nedenlerden ötürü çeşitli türdeki doğrusal ve doğrusal olmayan denklemleri çözebilmek için birçok sayısal yöntem geliştirilmiştir. Bu çalışmada, literatürde sıkça kullanılan sayısal yöntemlerden; diferansiyel kareleme (DKY), diferansiyel dönüşüm (DDY) ve sonlu farklar (SFY) yöntemleri algoritmaları ile kısaca anlatılmış ve kiriş ve plakanın modal analizi için uygulanarak sonuçları birbirleriyle karşılaştırılmıştır. Seçilen yapısal elemanlarda kesme gerinmesi etkileri ihmal edilmiş, plaka elemanlar ise basit mesnetli sınır koşulu kullanılarak tek boyutlu duruma indirgenmiştir. Bu varsayımlar altında, anlatılmakta olan sayısal yöntemler uygulanarak boyutsuz doğal frekanslar hesaplanarak tablolaştırılmış ve mod şekilleri çizdirilmiş. Kullanılan yöntemlerin gücünü ve doğruluğunu anlamak için, yüksek titreşim modlarında sayısal sonuçlar irdelenmiş ve DDY'nin daha hızlı ve daha doğru çözümler verdiği, DQM'nin sonuçlarının ise seçilen düğüm noktaları dağılımına bağlı olduğu ve dolasyısıyla DDY'den daha az doğru olduğu görülmüştür. Ancak, uygulama kolaylığı ve çok boyutlu durumlar için doğru sonuçlar DKY'nin olumlu özellikleridir.

Anahtar Kelimeler: Dinamik Karakteristikler, Diferansiyel Kareleme, Diferansiyel Dönüşüm, Euler Kiriş, Kirchhoff Plaka, Sonlu Farklar.

* Corresponding Author: yavuzmusta@itu.edu.tr 


\section{Introduction}

Solving partial and ordinary differential equations with satisfactory accuracy in structural mechanics or other fields of engineering is always a challenge for engineers in the last few decades. Therefore, numerous global and local numerical methods such as Adomian Decomposition, Differential Quadrature, Differential Transform, Finite Difference, Mesh Free Galerkin, Dynamic Stiffness, Transfer Matrix, Discrete Singular Convolution, Fourier Series, Rayleigh-Ritz, and ChebyshevWavelet, etc. have been developed to solve a variety of complicated engineering problems in the literature. Of these numerical approaches, Bellman et al. (1972) firstly introduced the differential quadrature method (DQM) to solve various nonlinear partial differential equations accurately by transforming them into a set of algebraic expressions, and many researchers contributed to the development of this method in the following years. In this technique, approximate the derivatives of a differential function at a grid point are expressed by using weighting coefficients, and then weighted coefficients of all grid points in the discretized domain are summed to find a weighted linear sum of the function. For many problems discussed in the papers (Civan and Sliepcevich, 1984; Wang and Bert, 1993; Wang et al., 1993; Du et al., 1994; Du et al., 1995; Malik and Bert, 1996; Shu and Du, 1997; Tornabene et al., 2009; Arikoglu and Ozkol, 2012; Tornabene et al., 2015; Yavuz and Ozkol, 2021), the technique gives satisfactory results in the case of chosen well-optimized spaces between grid points and well-determined weighting coefficients for suitable approximation functions. Ease of implementation of linear/nonlinear boundary conditions, less expensive computation methodology, low memory requests, simple algorithm scheme, solvability of complex geometries is a few of the prominent features.

The differential transformation method (DTM) is another technique frequently used in computational mechanics, which is first introduced through Zhou's circuit analysis studies (1986). By using this technique, the governing differential equations are transformed into recurrence relations with the help of a differential transformation table, and boundary conditions are stated as algebraic equations. Then, semi-analytical and numerical solutions based on Taylor series expansion are obtained for interested differential equations. In recent years, voluminous studies, especially related to vibration analysis of onedimensional structures (Malik and Dang, 1998; Malik and Allali, 200; Chen and Ho, 1996; Chen and Ho, 1999 Yeh et al., 2006; Yalcin et al., 2009; Jang et al., 2001; Arikoglu and Ozkol, 2010), have been published due to promising highly accurate or exact results in a short time.

The last method presented in this study is the finite difference method (FDM), which is the oldest -but still very usefulnumerical method for the solution of differential equations. In this technique, differential equations and boundary conditions are stated as finite differences at a set of interconnected nodes within the computational domain. Similar to DQM, governing differential equations are expressed by a set of simultaneous algebraic equations, so the solution can be calculated easily by the computers.

The objective of this study is to present a benchmark between the concerned method used in the determination of dynamic characteristics of structural elements before solving more complicated engineering problems and share the algorithm schemes of these methods.

The study is organized as follows. In section 2, the governing differential equations for beam and plate elements with no shear stress assumption are expressed. In Section 3, numerical methods used in the modal analysis with the algorithms and discretized differential equations up to the concerning methods are given. In section 4, mode shapes and non-dimensional natural frequencies of the structural elements are presented. Ultimately, the effect of boundary conditions, aspect ratio on the frequencies are investigated, and methods are compared with each other in the aspect of error and computation time.

\section{Governing Differential Equations}

In this section, the governing differential equations and boundary conditions for classical beam and plate theory are given in a non-dimensional form. Under these theories, it is assumed that beam and plate have no shear strains, are made of homogenous material, and have plane symmetry after deformation.

\subsection{Euler-Bernoulli Beam}

In one dimensional case, the Euler-Bernoulli beam model is preferred due to being the simplest beam model in the literature and giving reasonable results to demonstrate one-dimensional application. The mathematical model of the beam for free vibration can be given as.

$$
\rho A \frac{\partial^{2} w(x, t)}{\partial t^{2}}+E I \frac{\partial^{4} w(x, t)}{\partial x^{4}}=0
$$

In a non-dimensional form, the governing differential equation of the Euler-Bernoulli beam with uniform cross-section and length L can be obtained by separating Equation (1) into two ODEs and given for free harmonic vibration as

$$
\frac{d^{4} w(x)}{d x^{4}}-\Omega^{2} w(x)=0
$$

where $x$ is the non-dimensional coordinate along the axis of the beam, $w(x)$ is non-dimensional deflection, and $\Omega$ is the nondimensional frequency of vibration. The boundary conditions (BCs) at the edges of the beam may be one of the following; clamped (C), simply-supported (S), and free (F). These conditions in non-dimensional coordinates for the edges $x=0$, and $x=1$ can be given as

Table 1. Boundary conditions at the edges of the beam

\begin{tabular}{|l|l|ll|}
\hline$B C s$ & Edges & Boundary Equations \\
\hline Clamped & $x=0,1$ & $w=0$, & $\frac{d w}{d x}=0$ \\
\hline $\begin{array}{l}\text { Simply- } \\
\text { supported }\end{array}$ & $x=0,1$ & $w=0$, & $\frac{d^{2} w}{d x^{2}}=0$ \\
\hline Free & $x=0,1$ & $\frac{d^{2} w}{d x^{2}}=0$, & $\frac{d^{3} w}{d x^{3}}=0$ \\
\hline
\end{tabular}




\subsection{Kirchoff-Love Plate}

In two dimensional case, the simplest plate model is Kirchoff-Love or classical plate theory. The mathematical model of the thin rectangular plate for free vibration can be given as

$$
\rho h \frac{\partial^{2} w(x, y, t)}{\partial t^{2}}+D \nabla^{4} w(x, y, t)=0
$$

The governing differential equation of the plate in Equation (3) can be obtained by using the separation of variables method in a nondimensional form, and it can be given as

$$
\frac{\partial^{4} w(x, y)}{\partial x^{4}}+2 \lambda^{2} \frac{\partial^{4} w(x, y)}{\partial x^{2} \partial y^{2}}+. \lambda^{4} \frac{\partial^{4} w(x, y)}{\partial y^{4}}-\Omega^{2} w=0
$$

where $x$ and $y$ are the non-dimensional coordinates, $w(x, y)$ is nondimensional deflection, $\lambda=a / b$ is the length ratio, and $\Omega$ is the non-dimensional frequency of vibration. In nondimensional coordinates, the boundary conditions at the edges of the plate are presented as

\begin{tabular}{|c|c|c|}
\hline$B C s$ & Edges & Boundary Equations \\
\hline \multirow{2}{*}{ Clamped } & $x=0,1$ & $w=0, \frac{\partial w}{\partial x}=0$ \\
\hline & $y=0,1$ & $w=0, \frac{\partial w}{\partial y}=0$ \\
\hline \multirow{2}{*}{$\begin{array}{l}\text { Simply- } \\
\text { supported }\end{array}$} & $x=0,1$ & $w=0, \frac{\partial^{2} w}{\partial x^{2}}=0$ \\
\hline & $y=0,1$ & $w=0, \frac{\partial^{2} w}{\partial y^{2}}=0$ \\
\hline \multirow{2}{*}{ Free } & $x=0,1$ & $\begin{array}{l}\frac{\partial^{2} w}{\partial x^{2}}+v \lambda^{2} \frac{\partial^{2} w}{\partial y^{2}}=0, \\
\frac{\partial^{3} w}{\partial x^{3}}+(2-v) \lambda^{2} \frac{\partial^{3} w}{\partial x \partial y^{2}}=0\end{array}$ \\
\hline & $y=0,1$ & $\begin{array}{l}\lambda^{2} \frac{\partial^{2} w}{\partial y^{2}}+v \frac{\partial^{2} w}{\partial x^{2}}=0 \\
\lambda^{2} \frac{\partial^{3} w}{\partial y^{3}}+(2-v) \frac{\partial^{3} w}{\partial x^{2} \partial y}=0\end{array}$ \\
\hline
\end{tabular}

Table 2. Boundary conditions at the edges of the plate

\section{Numerical Approaches}

In this part of the study, concerned numerical methods are briefly discussed, and numerical solutions of beam and plate elements are given.

\subsection{Differential Quadrature Method}

In the differential quadrature method, values of approximate derivatives at any location of mesh are computed by summing linear weighted coefficients as follows

$$
\begin{gathered}
\left.\frac{\partial^{n} w(x, y)}{\partial x^{n}}\right|_{\substack{x=x_{i} \\
y=y_{j}}}=\sum_{k=1}^{N_{x}} A_{i k}^{(n)} w\left(x_{k}, y_{j}\right) \\
\left.\frac{\partial^{m} w(x, y)}{\partial y^{m}}\right|_{\substack{x=x_{i}, y=y_{j}}}=\sum_{l=1}^{N_{y}} B_{j l}^{(m)} w\left(x_{i}, y_{l}\right) \\
\left.\frac{\partial^{n+m} w(x, y)}{\partial x^{n} \partial y^{m}}\right|_{\substack{x=x_{i}, y=y_{j}}}=\sum_{k=1}^{N_{x}} A_{i k}^{(n)} \sum_{l=1}^{N_{y}} B_{j l}^{(m)} w\left(x_{k}, y_{l}\right)
\end{gathered}
$$

where first-order weighted coefficients are computed by Shu's approach (Shu, 2000) as

$$
A_{i k}^{(1)}= \begin{cases}\frac{\prod_{h=1, h \neq i}^{N_{x}}\left(x_{i}-x_{h}\right)}{\left(x_{i}-x_{k}\right) \prod_{h=1, h \neq k}^{N_{x}}\left(x_{k}-x_{h}\right)}, & \\ -\sum_{k=1, k \neq i}^{N_{x}} A_{i k}^{(n)}, & i \neq k\end{cases}
$$

$$
B_{j l}^{(1)}= \begin{cases}\frac{\prod_{h=1, h \neq j}^{N_{y}}\left(y_{j}-y_{h}\right)}{\left(y_{j}-y_{l}\right) \prod_{h=1, h \neq l}^{N_{y}}\left(y_{l}-y_{h}\right)}, & \\ -\sum_{l=1, l \neq i}^{N_{y}} B_{j l}^{(n)}, & j=l\end{cases}
$$

To find the weighted coefficients of the higher-order or hybrid derivatives, the following matrix multiplications can be done

$$
\begin{gathered}
A^{(a)}=A^{(b)} A^{(c)}, a=b+c, \quad b, c \in Z^{+} \\
B^{(d)}=B^{(e)} B^{(f)}, \quad d=e+f, \quad e, f \in Z^{+} \\
C^{(g)}=A^{(h)} B^{(i)}, \quad g=h+i, \quad h, i \in Z^{+}
\end{gathered}
$$

To obtain better results, the grid spacing of mesh can be done denser on boundaries by using Chebyshev-Gauss-Lobatto (CGL) grid distribution.

\subsubsection{Application of DQM to Beam Element}

As known, the DQM is a numerical computation technique based on discretization. Therefore, the equation of motion (EOM) can be discretized by using uniform or nonuniform (CGL) grid distribution. In this way, the continuous expression in Equation (2) turns into a combination of approximated functional values at grid points given in Equation (13).

$$
w^{(4)}\left(x_{i}\right)-\Omega^{2} w\left(x_{i}\right)=0
$$


Using the differential quadrature method, the discretized EOM can be written as

$$
w^{(4)}\left(x_{i}\right)-\Omega^{2} w\left(x_{i}\right)=0
$$

In matrix form, discretized expression can be rewritten as

$$
\left[c_{i j}^{(4)}-\Omega^{2} I\right]_{N \times N}\left[w\left(x_{j}\right)\right]_{N \times 1}=0
$$

The discretized boundary conditions of the beam at the edges are presented in Table 3. To implement the boundary conditions on the discretized EOM, the direct substitution of boundary conditions into the discrete governing equation in Equation (15)

Table 3. Discretized BCs at the edges of the beam

\begin{tabular}{|c|l|l|}
\hline BCs & & Boundary Equations \\
\hline \multirow{2}{*}{$\mathrm{C}$} & $i=1$ & $w_{1}=0, \sum_{j=1}^{N} c_{1 j}^{(1)} \cdot w\left(x_{j}\right)=0$ \\
\cline { 2 - 4 } & $i=N$ & $w_{N}=0, \sum_{j=1}^{N} c_{N j}^{(1)} \cdot w\left(x_{j}\right)=0$ \\
\hline \multirow{2}{*}{$\mathrm{S}$} & $i=1$ & $w_{1}=0, \sum_{j=1}^{N} c_{1 j}^{(2)} \cdot w\left(x_{j}\right)=0$ \\
\cline { 2 - 4 } & $i=N$ & $w_{N}=0, \sum_{j=1}^{N} c_{N j}^{(2)} \cdot w\left(x_{j}\right)=0$ \\
\hline \multirow{2}{*}{$\mathrm{F}$} & $i=1$ & $\sum_{j=1}^{N} c_{1 j}^{(2)} \cdot w\left(x_{j}\right)=0, \sum_{j=1}^{N} c_{1 j}^{(3)} \cdot w\left(x_{j}\right)=0$ \\
\cline { 2 - 4 } & $i=N$ & $\sum_{j=1}^{N} c_{N j}^{(2)} \cdot w\left(x_{j}\right)=0, \sum_{j=1}^{N} c_{N j}^{(3)} \cdot w\left(x_{j}\right)=0$ \\
\hline
\end{tabular}

\subsubsection{Application of DQM to Plate Element}

To illustrate the two-dimensional application of DQM, free vibration analysis of the thin rectangular plate under Kirchhoff's assumptions is considered. Differently from the one-dimensional case, there are used two different weighted coefficients to the directions, because of different sizes and directions of grid distributions. These coefficients can be expressed as

$$
\left.\frac{\partial^{r} w}{\partial x^{r}}\right|_{x=x_{i}}=\sum_{k=1}^{N} A_{i k}^{(r)} w_{k j},\left.\frac{\partial^{s} w}{\partial y^{s}}\right|_{y=y_{j}}=\sum_{l=1}^{N} B_{j l}^{(s)} w_{i l}
$$

Using the differential quadrature method, the EOM in Equation (4) can be discretized as

$$
\begin{aligned}
& \sum_{k=1}^{N} A_{i k}^{(4)} w_{k j}+2 \beta^{2} \sum_{l=1}^{M} B_{j l}^{(2)} \sum_{k=1}^{N} A_{i k}^{(2)} w_{k l}+\ldots \\
& \beta^{4} \sum_{l=1}^{M} B_{j l}^{(4)} w_{i l}=\Omega^{2} w_{i j}
\end{aligned}
$$

\begin{tabular}{|c|c|}
\hline$B C s$ & Boundary Equations \\
\hline \multirow{2}{*}{$\mathrm{C}$} & $w_{1, j}=\sum_{k=1}^{N} A_{1, k}^{(1)} w_{k, j}=0, w_{N, j}=\sum_{k=1}^{N} A_{N, k}^{(1)} w_{k, j}=0$ \\
\hline & $w_{i, 1}=\sum_{k=1}^{N} B_{1, k}^{(1)} w_{i, k}=0, w_{i, M}=\sum_{k=1}^{N} B_{M, k}^{(1)} w_{i, k}=0$ \\
\hline \multirow{2}{*}{$S$} & $w_{1, j}=\sum_{k=1}^{N} A_{1, k}^{(2)} w_{k, j}=0, w_{N, j}=\sum_{k=1}^{N} A_{N, k}^{(2)} w_{k, j}=0$ \\
\hline & $w_{i, 1}=\sum_{k=1}^{N} B_{1, k}^{(2)} w_{i, k}=0, w_{i, M}=\sum_{k=1}^{N} B_{M, k}^{(2)} w_{i, k}=0$ \\
\hline \multirow{4}{*}{$\mathrm{F}$} & $\begin{array}{l}\sum_{k=1}^{N} A_{1 k}^{(2)} w_{k j}+v \lambda^{2} \sum_{l=1}^{M} B_{j l}^{(2)} \sum_{k=1}^{N} A_{i k}^{(2)} w_{k l}=0 \\
\sum_{k=1}^{N} A_{1 k}^{(3)} w_{k j}+(2-v) \lambda^{2} \sum_{l=1}^{M} B_{j l}^{(2)} \sum_{k=1}^{N} A_{1 k}^{(1)} w_{k l}=0\end{array}$ \\
\hline & $\begin{array}{l}\sum_{k=1}^{N} A_{N, k}^{(2)} w_{k, j}+v \lambda^{2} \sum_{k=1}^{N} A_{i k}^{(2)} w_{k 1}=0, \\
\sum_{k=1}^{N} A_{N, k}^{(3)} w_{k, j}+(2-v) \lambda^{2} \sum_{l=1}^{M} B_{j l}^{(2)} \sum_{k=1}^{N} A_{N k}^{(1)} w_{k l}=0\end{array}$ \\
\hline & $\begin{array}{l}\lambda^{2} \sum_{k=1}^{N} B_{1 k}^{(2)} w_{i k}+v \sum_{k=1}^{N} A_{i k}^{(2)} w_{k 1}=0 \\
\lambda^{2} \sum_{k=1}^{N} B_{1 k}^{(3)} w_{i k}+(2-v) \sum_{l=1}^{M} B_{j l}^{(1)} \sum_{k=1}^{N} A_{1 k}^{(2)} w_{k l}=0\end{array}$ \\
\hline & $\begin{array}{l}\lambda^{2} \sum_{k=1}^{N} B_{M, k}^{(2)} w_{i, k}+v \sum_{k=1}^{N} A_{i k}^{(2)} w_{k 1}=0 \\
\lambda^{2} \sum_{k=1}^{N} B_{M, k}^{(3)} w_{i, k}+(2-v) \sum_{l=1}^{M} B_{j l}^{(1)} \sum_{k=1}^{N} A_{i k}^{(2)} w_{k l}=0\end{array}$ \\
\hline
\end{tabular}

The discretized boundary conditions of the plate at the edges are presented in Table 4.
Table 4. Discretized BCs at the edges of the plate

\subsection{Differential Transform Method}

In the differential transform method (DTM), the $k^{\text {th }}$ derivative of function $w(x)$ is defined as

$$
W(k)=\frac{1}{k !}\left[\frac{d^{k} w(x)}{d x^{k}}\right]_{x=x_{0}}
$$

where $W(k)$ is the transformed function of $w(x)$. Also, the inverse differential transform of the $W(k)$ function is defined as

$$
w(x)=\sum_{k=0}^{\infty}\left(x-x_{0}\right)^{k} W(k)
$$

According to definitions given above, any function can be written as Taylor series expansion 


$$
w(x)=\sum_{k=0}^{\infty} \frac{\left(x-x_{0}\right)^{k}}{k !}\left[\frac{d^{k} w(x)}{d x^{k}}\right]_{x=x_{0}}
$$

From these definitions, fundamental theorems of DTM can be proved, which are given in Table 5. The algorithm flowchart of DTM is given in Figure 2.

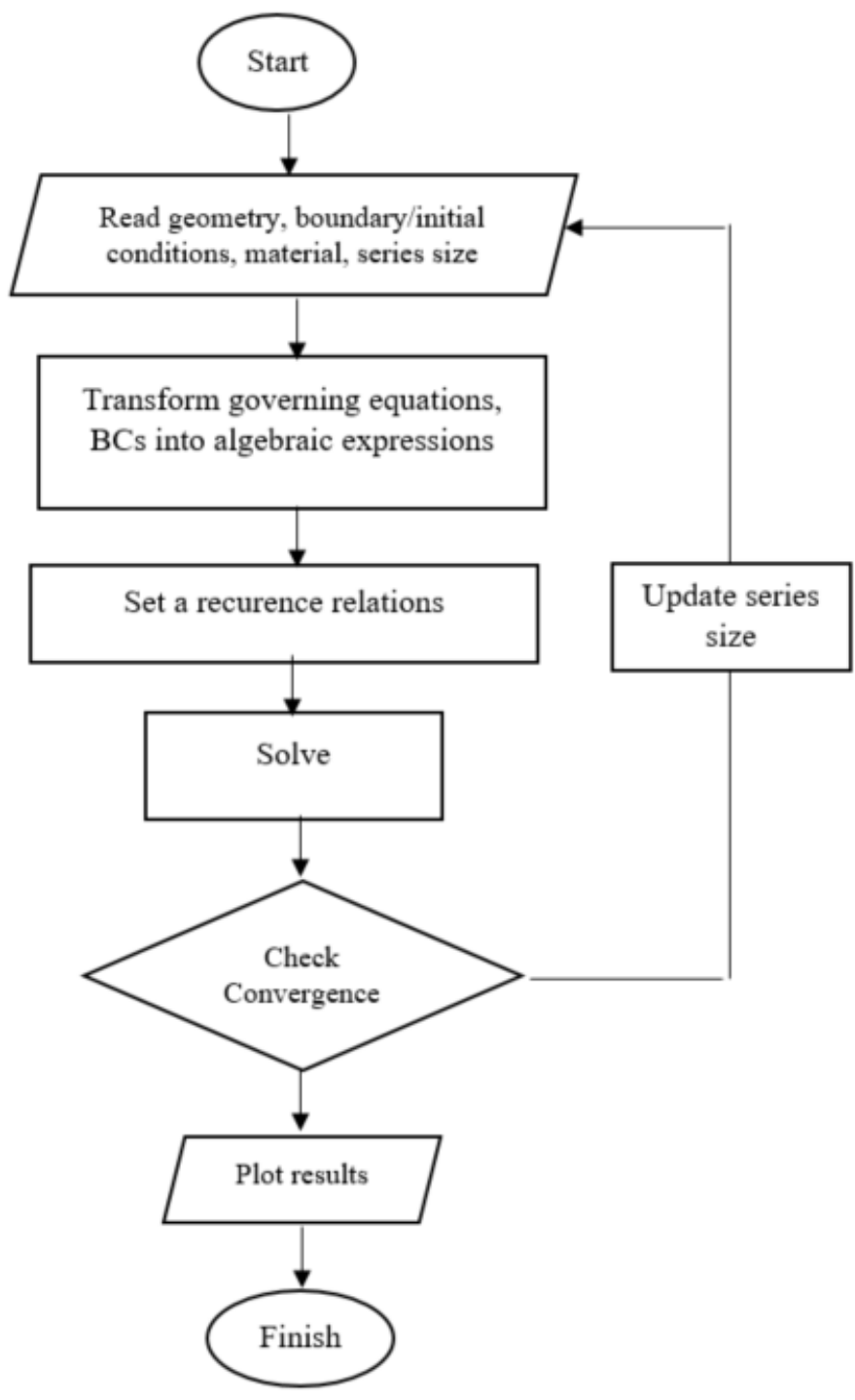

Figure 2. DTM algorithm's flowchart

Table 6. Fundamental Operations (Hatami,2017)

\begin{tabular}{ll}
\hline Original Function & Transformed Function \\
\hline$f(x)=g(x) \pm h(x)$ & $F(k)=G(k) \pm H(k)$ \\
$f(x)=\operatorname{cg}(x)$ & $F(k)=c G(k)$ \\
$f(x)=x^{n}$ & $F(k)=\frac{a^{k}}{k !} \sin \left(\frac{\pi}{2} k+b\right)$ \\
$f(x)=\sin (a x+b)$ & $F(k)=\frac{(k+n) !}{k !} G(k)$ \\
$f(x)=\frac{d^{n} g(x)}{d x^{n}}$ & $F(k)=\sum_{l=0}^{k} G(l) H(k-l)$ \\
$f(x)=g(x) h(x)$ &
\end{tabular}

\subsubsection{Application of DTM to Beam Element}

Using the transform rules given in Table 6 , the equation of motion in Equation (2) can be transformed into the following recurrence relation,

$$
W(k+4)=\frac{\Omega^{2}}{(k+4)(k+3)(k+2)(k+1)} W(k)
$$

The boundary conditions are transformed into algebraic equations about a point $\mathrm{x}_{0}=0$ by using definitions of transformation technique in Equations (18) and (19), and presented in Table 7.

Table 7. Transformed BCs for the beam

\begin{tabular}{|c|c|l|}
\hline $\boldsymbol{B C} \boldsymbol{s}$ & \multicolumn{1}{|c|}{$x=0$} & \multicolumn{1}{c|}{$x=1$} \\
\hline $\mathrm{C}$ & $W(0)=0$, & $\sum_{k=0}^{N} W(k)=0$, \\
& $W(1)=0$ & $\sum_{k=0}^{N} k W(k)=0$ \\
\hline $\mathrm{S}$ & $W(0)=0$, & $\sum_{k=0}^{N} W(k)=0$, \\
& $W(2)=0$ & $\sum_{k=0}^{N} k(k-1) W(k)=0$ \\
$\mathrm{~F}$ & $W(2)=0$, & $\sum_{k=0}^{N} k(k-1) W(k)=0$, \\
& $W(3)=0$ & $\sum_{k=0}^{N} k(k-1)(k-2) W(k)=0$ \\
\hline
\end{tabular}

By substituting algebraic equations defined for boundary conditions into recurrence relation given in Equation (21), the solution can be found.

\subsubsection{Application of DTM to Plate Element}

Due to difficulties in obtaining simplified recurrence relations between boundary conditions and governing differential equations, the equation of motion (EOM) in Equation (4) is reduced to one-dimensional expression for simply-supported boundaries at both ends of the plate as following [16]

$$
\frac{\partial^{4} w}{\partial y^{4}}-2 \varphi \frac{\partial^{2} w}{\partial y^{2}}-\psi w(y)=0
$$

where $\varphi=\left(\frac{\sigma \pi}{\lambda}\right)^{2}, \quad \psi=\frac{\Omega^{2}}{\lambda^{4}}-\left(\frac{\sigma \pi}{\lambda}\right)^{4}$

For the reduced governing equation, the boundary conditions of the plate are given in Table 8. According to these BCs, the solution is found by using DTM. 
Table 8. BCs for the plate along $y=0$, and $y=1$ sides [16]

\begin{tabular}{|l|l|}
\hline BCs & Boundary Equations \\
\hline Clamped & $w(y)=0, \frac{d w(y)}{d y}=0$ \\
\hline $\begin{array}{l}\text { Simply- } \\
\text { supported }\end{array}$ & $w(y)=0, \frac{d^{2} w(y)}{d y^{2}}=0$ \\
\hline Free & $\frac{d^{2} w(y)}{d y^{2}}-\alpha w(y)=0, \alpha=v\left(\frac{\sigma \pi}{\lambda}\right)^{2}$ \\
& $\frac{d^{3} w(y)}{d y^{3}}-\beta \frac{d w(y)}{d y}=0, \beta=(2-v)\left(\frac{\sigma \pi}{\lambda}\right)^{2}$ \\
\hline
\end{tabular}

Using the transformation rules given in Table 6, the equation of motion in Equation (22) can be transformed into the following equation,

$$
\frac{(h+4) !}{h !} W(h+4)-\frac{2 \varphi(h+2) !}{h !} W(h+2)-\psi W(h)=0
$$

The boundary conditions are transformed into algebraic equations about a point $\mathrm{y}_{0}$ by using definitions of a transformation technique, which are presented in Table 9.

Table 9. Transformed BCs for the plate [16]

\begin{tabular}{|c|l|l|}
\hline $\boldsymbol{B C}$ & $y=0$ & $y=1$ \\
\hline $\mathrm{C}$ & $W(0)=0, W(1)=0$ & $\sum_{h=0}^{M} W=0, \sum_{h=0}^{M} h W=0$ \\
\hline $\mathrm{S}$ & $W(0)=0, W(2)=0$ & $\sum_{h=0}^{M} W=0, \sum_{h=0}^{M} h(h-1) W=0$ \\
\hline $\mathrm{F}$ & $2 W(2)-\alpha W(0)=0$ & $\sum_{h=0}^{M}\{h(h-1)-\alpha\} W=0$ \\
& $6 W(3)-\beta W(1)=0$ & $\sum_{h=0}^{M}\{h(h-1)(h-2)-\beta\} W=0$ \\
\hline
\end{tabular}

In a similar way to the solution of the beam, the solution can be found for S-F, C-C, C-S, S-S, C-F, and F-F boundary conditions along y sides. To simplify the EOM of the plate, the boundaries along $\mathrm{x}$ sides are assumed as simply-supported boundaries so that the partial differential equation of EOM in Equation (4) can be reduced to the ordinary differential equation.

\subsection{Finite Difference Method}

Stating approximate derivatives by the means of finite differences is the key point of the finite difference method (FDM), which is given for one-dimensional case as follow

$$
\begin{aligned}
& \left(\frac{d w}{d x}\right)_{i}=\lim _{\Delta x \rightarrow 0} \frac{w_{i+1}-w_{i}}{\Delta x} \approx \frac{w\left(x_{i}+\Delta x\right)-w\left(x_{i}\right)}{\Delta x}=\frac{\Delta w_{i}}{h} \\
& \left(\frac{d w}{d x}\right)_{i}=\lim _{\Delta x \rightarrow 0} \frac{w_{i}-w_{i-1}}{\Delta x} \approx \frac{w\left(x_{i}\right)-w\left(x_{i}+\Delta x\right)}{\Delta x}=\frac{\nabla w_{i}}{h} \\
& \left(\frac{d w}{d x}\right)_{i}=\lim _{\Delta x \rightarrow 0} \frac{w_{i+1}-w_{i-1}}{2 \Delta x} \approx \frac{w\left(x_{i}+\Delta x\right)-w\left(x_{i}-\Delta x\right)}{2 \Delta x}
\end{aligned}
$$

where forward, backward, and central differences are given, respectively. $i$ denotes any arbitrary point on the curve, $\Delta$ forward difference operator, and $\nabla$ backward difference operator. Of them, the central difference gives a more accurate approximation of derivatives due to grid points symmetrically distributed around the $\mathrm{x}_{\mathrm{i}}$. Therefore, structural elements are solved by using central difference and the following algorithm in Figure 3.

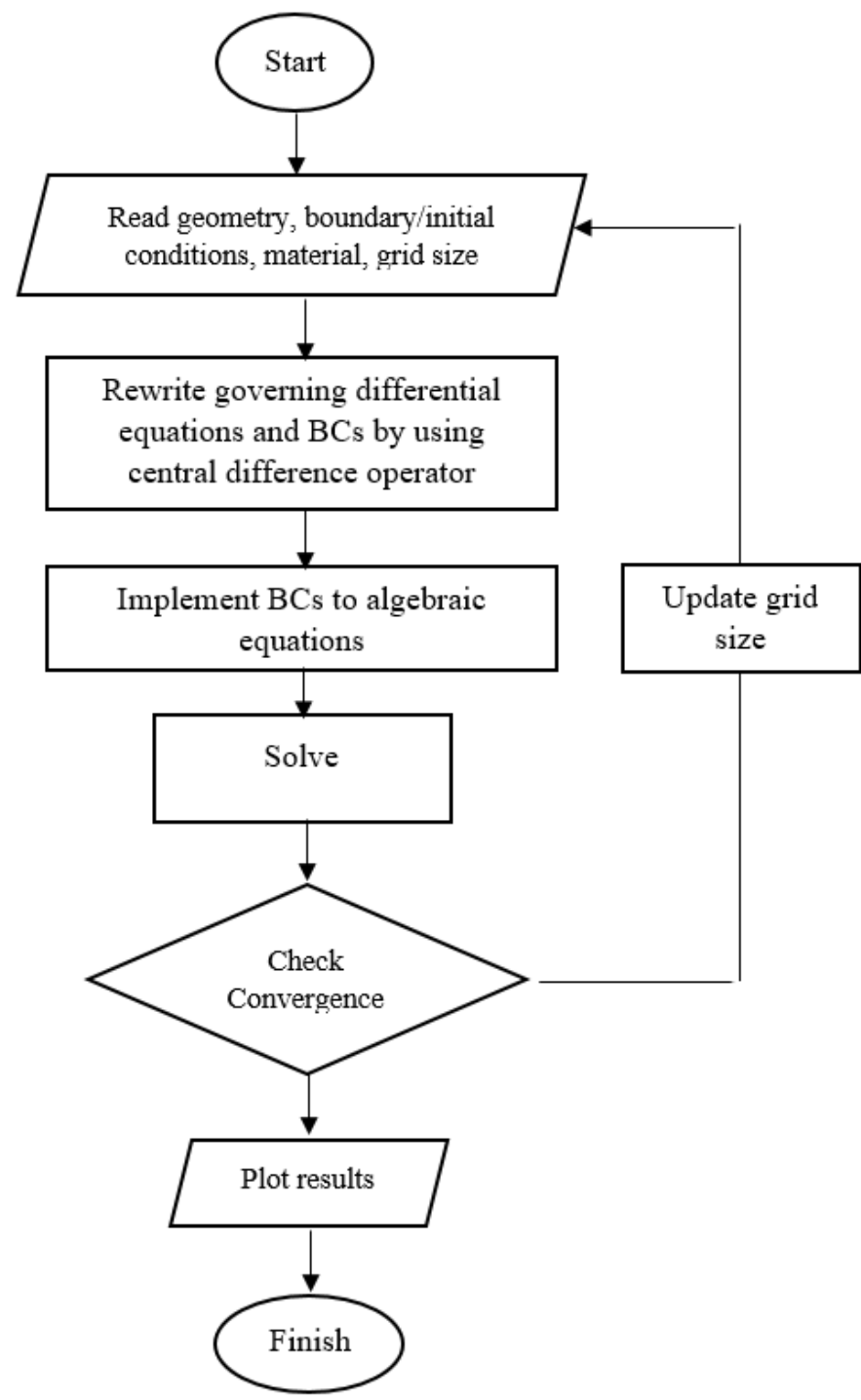

Figure 3. FDM algorithm's flowchart

\subsubsection{Application of FDM to Beam Element}

Using the finite difference method, the discretized EOM for the beam can be written as 


$$
\frac{w_{i+2}-4 w_{i+1}+6 w_{i}-4 w_{i-1}+w_{i-2}}{(\Delta x)^{4}}-\Omega^{2} w_{i}=0
$$

Similarly, the boundary conditions are written via central difference, and implement into Equation (26) by updating stencil points.

\subsubsection{Application of FDM to Plate Element}

The discretized EOM of the thin isotropic rectangular plate for transverse vibration is expressed as follows

$$
\begin{aligned}
& \frac{w_{i+2, j}-4 w_{i+1, j}+6 w_{i, j}-4 w_{i-1, j}+w_{i-2, j}}{(\Delta x)^{4}}+\ldots \\
& 2 \lambda^{2} \frac{w_{i+1, j+1}-2 w_{i, j+1}+w_{i-1, j+1}-2 w_{i+1, j}}{(\Delta x)^{2}(\Delta y)^{2}}+\ldots \\
& 2 \lambda^{2} \frac{4 w_{i, j}-2 w_{i-1, j}+w_{i+1, j-1}-2 w_{i, j-1}+w_{i-1, j-1}}{(\Delta x)^{2}(\Delta y)^{2}}+\ldots \\
& \lambda^{4} \frac{w_{i, j+2}-4 w_{i, j+1}+6 w_{i, j}-4 w_{i, j-1}+w_{i, j-2}}{(\Delta y)^{4}}-\Omega^{2} w_{i, j}=0
\end{aligned}
$$

Similarly, the boundary conditions are written via central difference, and implement into Equation (26) by updating algebraic equations in the matrix form.

\section{Results and Discussion}

To determine the dynamic characteristics of one and twodimensional structural elements, mesh-free methods i.e. DQM and DTM, and meshed method i.e. FDM are employed, and then numerical solutions are compared for different boundary conditions, aspect ratios, term sizes used in computations, and absolute errors in this study. Meanwhile, short formulations of the methods and governing differential equations are given, and algorithm schemes of the employed methods are presented in Figures 1-3. Furthermore, convergence analysis in Figure 4 is given for different methods to understand which method is more efficient for computer memory usage, faster, and so on. Ultimately, non-dimensional natural frequencies for the beam and plate elements are tabulated, and the mode shapes are plotted in Figures 5-6.

In the last few years, DQM and DTM are two of the popular mesh-free methods attracting the interest of many researchers. On the other hand, FDM is one of the oldest but still useful global methods. In all methods, the governing differential equations of structural elements are transformed into algebraic equations, and then written in matrix format. Discretized boundary conditions according to concerning methods' algorithm are implemented to the system matrix by updating the rows. The difference between them is the approximation methodology to derivative terms. In Table 10, the non-dimensional natural frequencies of the beam are presented. According to this table, DTM gives the closest solution to analytical results in [26], so the absolute error of DTM is smaller than other two methods. According to boundaries at the ends of the beam, the highest non-dimensional natural frequencies are seen C-C and F-F boundaries, which are equal to each other, but mode shapes of them are different as seen in Figure 5. In two dimensional case, the effect of aspect ratio and boundary conditions are investigated. Up to the increasing aspect ratio in Table 11, the non-dimensional natural frequencies increase. Similarly, the smallest absolute error is seen for the solution realized by DTM for the special case mentioned above. Finally, convergence analysis in high mode is realized to understand which method is faster and needs less memory requirement. To results in Figure 6, DTM is the fastest method.
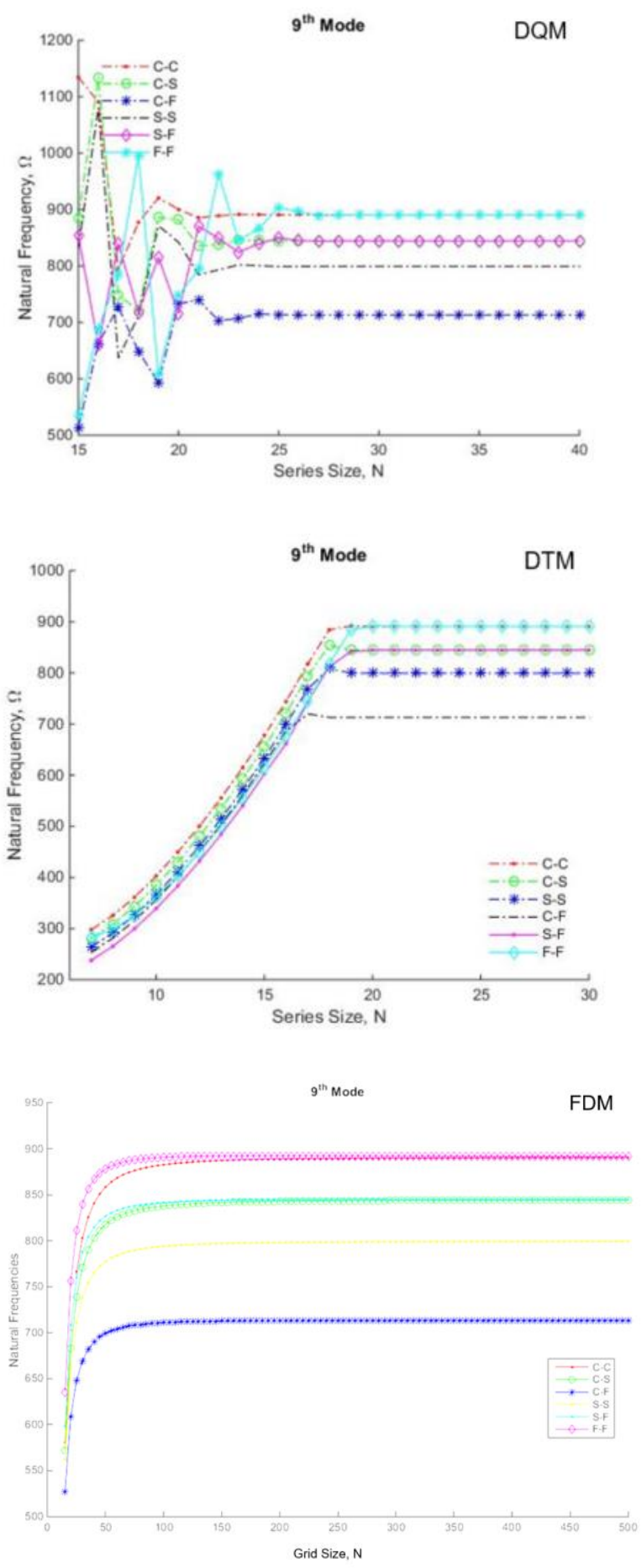

Figure 4. Convergence analysis of the non-dimensional natural frequencies of various beam elements for the $9^{\text {th }}$ mode. 

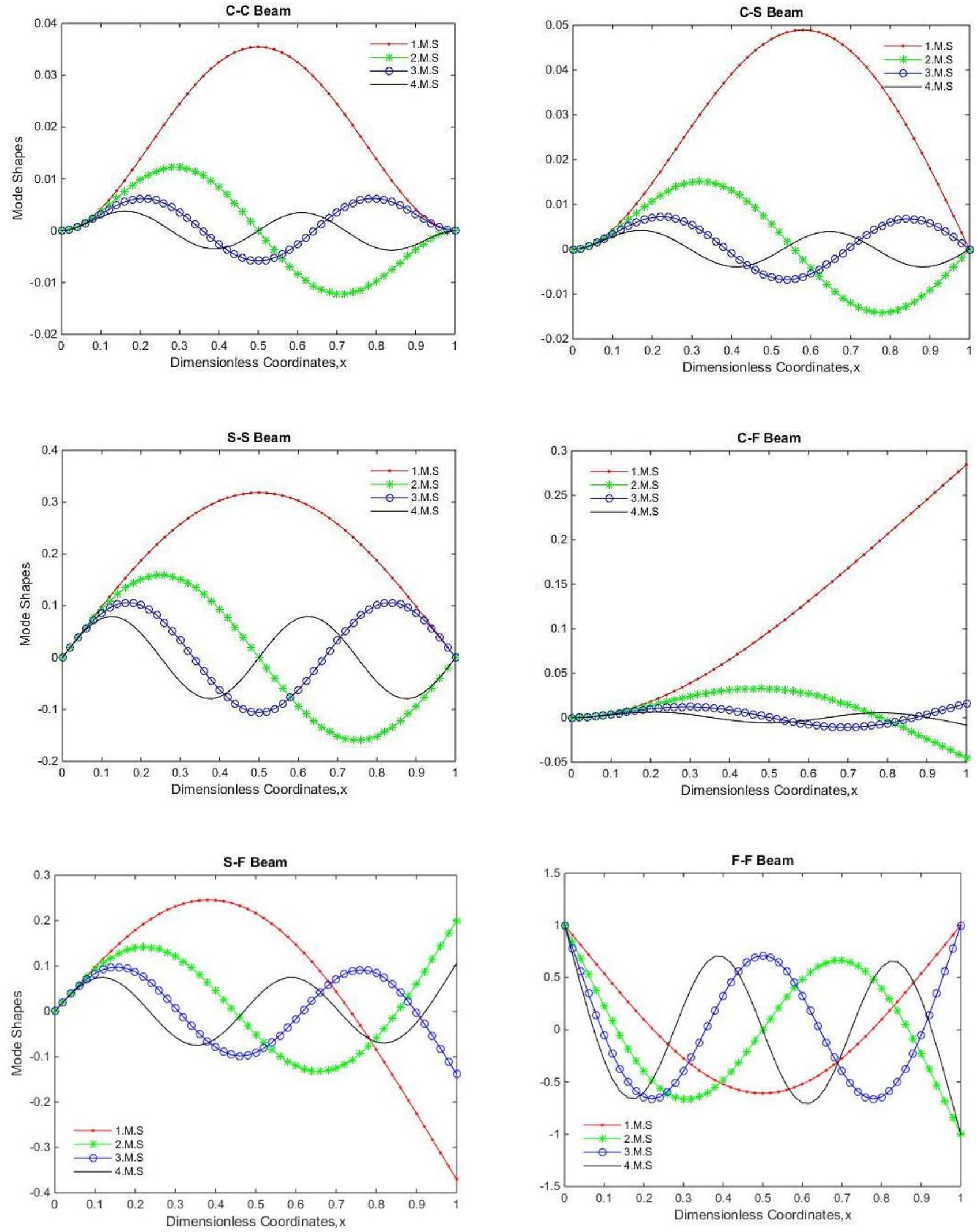

Figure 5. Mode shapes of the beam elements for different boundary conditions 
Table 10. Nondimensional natural frequencies of the beam elements for different boundary cases

\begin{tabular}{|c|c|c|c|c|c|c|c|c|c|c|}
\hline \multirow[t]{2}{*}{$\begin{array}{c}\text { Boundary } \\
\text { Conditions }\end{array}$} & \multicolumn{5}{|c|}{ Clamped-Clamped } & \multicolumn{5}{|c|}{ Simply Supported-Simply Supported } \\
\hline & Blevins & $\begin{array}{r}\text { DQM } \\
\text { (Uniform) } \\
\end{array}$ & $\begin{array}{l}\text { DQM } \\
\text { (CGL) }\end{array}$ & FDM & DTM & Blevins & $\begin{array}{r}\text { DQM } \\
\text { (Uniform) } \\
\end{array}$ & $\begin{array}{l}\text { DQM } \\
\text { (CGL) }\end{array}$ & FDM & DTM \\
\hline Mode & & & & & & & & & & \\
\hline $1^{\text {st }}$ & 22,3733 & 22,3733 & 22,3733 & 22,3732 & 22,3733 & 9,8696 & 9,8696 & 9,8696 & 9,8696 & 9,8696 \\
\hline $2^{\text {nd }}$ & 61,6728 & 61,6728 & 61,6728 & 61,6723 & 61,6728 & 39,4784 & 39,4784 & 39,4784 & 39,4783 & 39,4784 \\
\hline $3^{\text {rd }}$ & 120,9034 & 120,9034 & 120,9034 & 120,9015 & 120,9034 & 88,8264 & 88,8264 & 88,8264 & 88,8258 & 88,8264 \\
\hline $4^{\text {th }}$ & 199,8594 & 199,8607 & 199,8594 & 199,8547 & 199,8594 & 157,9137 & 157,9141 & 157,9137 & 157,9116 & 157,9137 \\
\hline $5^{\text {th }}$ & 298,5555 & 298,3357 & 298,5555 & 298,5455 & 298,5555 & 246,7401 & 246,6215 & 246,7399 & 246,7350 & 246,7401 \\
\hline $6^{\text {th }}$ & 416,9908 & 413,7238 & 416,9894 & 416,9720 & 416,9908 & 355,3058 & 353,2592 & 355,3022 & 355,2952 & 355,3058 \\
\hline $7^{\text {th }}$ & 555,1652 & 557,6415 & 555,1977 & 555,1330 & 555,1652 & 483,6106 & 491,1128 & 483,7155 & 483,5911 & 483,6106 \\
\hline $8^{\text {th }}$ & 713,0789 & 557,6415 & 713,3467 & 713,0269 & 713,0791 & 631,6547 & 491,1128 & 632,5268 & 631,6214 & 631,6546 \\
\hline $9^{\text {th }}$ & 890,7318 & 628,9425 & 889,0825 & 890,6522 & 890,7296 & 799,4380 & 560,2755 & 793,1577 & 799,3846 & 799,4388 \\
\hline $10^{\text {th }}$ & 1088,1239 & 628,9425 & 1077,2822 & 1088,0070 & 1088,0228 & 986,9604 & 560,2755 & 955,8531 & 986,8791 & 986,9305 \\
\hline
\end{tabular}

\begin{tabular}{|c|c|c|c|c|c|c|c|c|c|c|}
\hline \multirow{2}{*}{$\begin{array}{l}\text { Boundary } \\
\text { Conditions }\end{array}$} & \multicolumn{5}{|c|}{ Clamped-Simply Supported } & \multicolumn{5}{|c|}{ Clamped-Free } \\
\hline & Blevins & $\begin{array}{r}\text { DQM } \\
\text { (Uniform) } \\
\end{array}$ & $\begin{array}{l}\text { DQM } \\
\text { (CGL) }\end{array}$ & FDM & DTM & Blevins & $\begin{array}{r}\text { DQM } \\
\text { (Uniform) } \\
\end{array}$ & $\begin{array}{l}\text { DQM } \\
\text { (CGL) }\end{array}$ & FDM & DTM \\
\hline \multicolumn{11}{|l|}{ Mode } \\
\hline $1^{\mathrm{st}}$ & 15,4182 & 15,4180 & 15,4182 & 15,4182 & 15,4182 & 3,5160 & 3,5158 & 3,5160 & 3,5172 & 3,5160 \\
\hline $2^{\text {nd }}$ & 49,9648 & 49,9649 & 49,9649 & 49,9646 & 49,9649 & 22,0345 & 22,0345 & 22,0345 & 22,0418 & 22,0345 \\
\hline $3^{\text {rd }}$ & 104,2477 & 104,2477 & 104,2477 & 104,2465 & 104,2477 & 61,6972 & 61,6972 & 61,6972 & 61,7174 & 61,6972 \\
\hline $4^{\text {th }}$ & 178,2697 & 178,2699 & 178,2697 & 178,2665 & 178,2697 & 120,9019 & 120,9016 & 120,9019 & 120,9409 & 120,9019 \\
\hline $5^{\text {th }}$ & 272,0310 & 271,8292 & 272,0307 & 272,0237 & 272,0310 & 199,8595 & 199,8459 & 199,8594 & 199,9226 & 199,8595 \\
\hline $6^{\text {th }}$ & 385,5314 & 383,7956 & 385,5299 & 385,5171 & 385,5314 & 298,5555 & 300,0946 & 298,5655 & 298,6472 & 298,5555 \\
\hline $7^{\text {th }}$ & 518,7711 & 516,2124 & 518,8931 & 518,7456 & 518,7711 & 416,9908 & 429,3601 & 417,1064 & 417,1145 & 416,9908 \\
\hline $8^{\text {th }}$ & 671,7499 & 516,2124 & 672,2265 & 671,7079 & 671,7499 & 555,1652 & 429,3601 & 553,1932 & 555,3233 & 555,1652 \\
\hline $9^{\text {th }}$ & 844,4680 & 603,9060 & 837,7557 & 844,4023 & 844,4714 & 713,0789 & 591,1642 & 702,9631 & 713,2723 & 713,0796 \\
\hline $10^{\text {th }}$ & 1036,9253 & 603,9060 & 1018,5084 & 1036,8272 & 1036,7831 & 890,7318 & 591,1642 & 933,4812 & 890,9598 & 890,7162 \\
\hline
\end{tabular}

\begin{tabular}{|c|c|c|c|c|c|c|c|c|c|c|}
\hline \multirow[t]{2}{*}{$\begin{array}{l}\text { Boundary } \\
\text { Conditions }\end{array}$} & \multicolumn{5}{|c|}{ Simply Supported-Free } & \multicolumn{5}{|c|}{ Free-Free } \\
\hline & Blevins & $\begin{array}{r}\text { DQM } \\
\text { (Uniform) }\end{array}$ & $\begin{array}{l}\text { DQM } \\
\text { (CGL) }\end{array}$ & FDM & DTM & Blevins & $\begin{array}{r}\text { DQM } \\
\text { (Uniform) } \\
\end{array}$ & $\begin{array}{l}\text { DQM } \\
\text { (CGL) }\end{array}$ & FDM & DTM \\
\hline Mode & & & & & & & & & & \\
\hline $1^{\text {st }}$ & 15,4182 & 15,4182 & 15,4182 & 15,4233 & 15,4182 & 22,3733 & 22,3733 & 22,3733 & 22,3882 & 22,3733 \\
\hline $2^{\text {nd }}$ & 49,9649 & 49,9649 & 49,9649 & 49,9814 & 49,9649 & 61,6728 & 61,6776 & 61,6728 & 61,7138 & 61,6728 \\
\hline $3^{\text {rd }}$ & 104,2477 & 104,2476 & 104,2477 & 104,2817 & 104,2477 & 120,9034 & 120,9028 & 120,9034 & 120,9833 & 120,9034 \\
\hline $4^{\text {th }}$ & 178,2697 & 178,2605 & 178,2697 & 178,3269 & 178,2697 & 199,8594 & 199,8309 & 199,8592 & 199,9903 & 199,8594 \\
\hline $5^{\text {th }}$ & 272,0310 & 272,3689 & 272,0339 & 272,1162 & 272,0310 & 298,5555 & 302,1213 & 298,5756 & 298,7489 & 298,5555 \\
\hline $6^{\text {th }}$ & 385,5314 & 411,3388 & 385,6189 & 385,6487 & 385,5314 & 416,9908 & 427,4586 & 417,2233 & 417,2570 & 416,9908 \\
\hline $7^{\text {th }}$ & 518,7711 & 411,3388 & 518,1270 & 518,9234 & 518,7711 & 555,1652 & 440,5495 & 551,3529 & 555,5138 & 555,1653 \\
\hline $8^{\text {th }}$ & 671,7499 & 529,8806 & 663,0258 & 671,9389 & 671,7499 & 713,0789 & 440,5495 & 692,6267 & 713,5178 & 713,0791 \\
\hline $9^{\text {th }}$ & 844,4680 & 529,8806 & 849,2064 & 844,6937 & 844,4697 & 890,7318 & 593,5509 & 962,1214 & 891,2676 & 890,7264 \\
\hline $10^{\text {th }}$ & 1036,9253 & 626,7816 & 1039,1441 & 1037,1862 & 1036,9181 & 1088,1239 & 593,5509 & 962,1214 & 1088,7614 & 1086,1715 \\
\hline
\end{tabular}


European Journal of Science and Technology

Table 11. Nondimensional natural frequencies of the plate elements for different boundary cases and aspect ratios

\begin{tabular}{|c|c|c|c|c|c|c|c|c|c|c|c|c|c|c|c|c|}
\hline Boundar & & & & S-S-S-S & & & & & S-C-S-C & & & & & S-C-S-S & & \\
\hline & & & & $\mathbf{a} / \mathbf{b}$ & & & & & $\mathbf{a} / \mathbf{b}$ & & & & & $\mathbf{a} / \mathbf{b}$ & & \\
\hline Aspect Ka & & $2 / 5$ & $2 / 3$ & 1.0 & $3 / 2$ & $5 / 2$ & $2 / 5$ & $2 / 3$ & 1.0 & $3 / 2$ & $5 / 2$ & $2 / 5$ & $2 / 3$ & 1.0 & $3 / 2$ & $5 / 2$ \\
\hline & Leissa & 11,4487 & 14,2561 & 19,7392 & 32,0762 & 71,5564 & 12,1347 & 17,3730 & 28,9509 & 56,3481 & 145,4839 & 11,7502 & 15,5783 & 23,6463 & 42,5278 & 103,9227 \\
\hline $1^{\mathrm{st}}$ & DQM & 11,4487 & 14,2561 & 19,7392 & 32,0762 & 71,5546 & 12,1347 & 17,3730 & 28,9509 & 56,3481 & 145,4839 & 11,7502 & 15,5783 & 23,6463 & 42,5278 & 103,9227 \\
\hline $1^{32}$ & FDM & 11,4426 & 14,2484 & 19,7285 & 32,0589 & 71,5159 & 12,1347 & 17,3730 & 28,9509 & 56,3481 & 145,4839 & 11,7502 & 15,5783 & 23,6463 & 42,5278 & 103,9227 \\
\hline & DTM & 11,4487 & 14,2561 & 19,7392 & 32,0762 & 71,5546 & 12,1347 & 17,3730 & 28,9509 & 56,3481 & 145,4839 & 11,7502 & 15,5783 & 23,6463 & 42,5278 & 103,9227 \\
\hline & Leissa & 16,1862 & 27,4156 & 49,3480 & 61,6850 & 101,1634 & 18,3647 & 35,3445 & 54,7431 & 78,9836 & 164,7387 & 17,1872 & 31,0724 & 51,6743 & 69,0031 & 128,3382 \\
\hline & DQM & 16,1862 & 27,4156 & 49,3480 & 61,6850 & 101,1634 & 18,3647 & 35,3445 & 54,7431 & 78,9836 & 164,7387 & 17,1872 & 31,0724 & 51,6743 & 69,0031 & 128,3382 \\
\hline 2 & FDM & 16,1672 & 27,3723 & 49,2574 & 61,5877 & 101,0448 & 18,3647 & 35,3445 & 54,7431 & 78,9836 & 164,7387 & 17,1872 & 31,0724 & 51,6743 & 69,0031 & 128,3382 \\
\hline & DTM & 16,1862 & 27,4156 & 49,3480 & 61,6850 & 101,1634 & 18,3647 & 35,3445 & 54,7431 & 78,9836 & 164,7387 & 17,1872 & 31,0724 & 51,6743 & 69,0031 & 128,3382 \\
\hline & Leissa & 24,0818 & 43,8649 & 49,3480 & 98,6960 & 150,5115 & 27,9657 & 45,4294 & 69,3270 & 123,1719 & 202,2271 & 25,9171 & 44,5644 & 58,6464 & 116,2671 & 172,3804 \\
\hline $3^{\text {rd }}$ & DQM & 24,0818 & 43,8649 & 49,3480 & 98,6960 & 150,5115 & 27,9657 & 45,4294 & 69,3270 & 123,1719 & 202,2271 & 25,9171 & 44,5644 & 58,6464 & 116,2671 & 172,3804 \\
\hline 3 & FDM & 24,0075 & 43,7772 & 49,2574 & 98,4987 & 150,0467 & 27,9657 & 45,4294 & 69,3270 & 123,1719 & 202,2271 & 25,9171 & 44,5644 & 58,6464 & 116,2671 & 172,3804 \\
\hline & DTM & 24,0818 & 43,8649 & 49,3480 & 98,6960 & 150,5115 & 27,9657 & 45,4294 & 69,3270 & 123,1719 & 202,2271 & 25,9171 & 44,5644 & 58,6464 & 116,2671 & 172,3804 \\
\hline & Leissa & 35,1358 & 49,3480 & 78,9568 & 111,0330 & 219,5987 & 40,7500 & 62,0544 & 94,5853 & 146,2677 & 261,1053 & 37,8317 & 55,3926 & 86,1345 & 120,9956 & 237,2502 \\
\hline $4^{\text {th }}$ & DQM & 35,1358 & 49,3480 & 78,9568 & 111,0330 & 219,5987 & 40,7500 & 62,0544 & 94,5853 & 146,2677 & 261,1052 & 37,8317 & 55,3926 & 86,1345 & 120,9956 & 237,2502 \\
\hline 4 & FDM & 34,9126 & 49,1509 & 78,7862 & 110,5896 & 218,2038 & 40,7500 & 62,0544 & 94,5853 & 146,2677 & 261,1053 & 37,8317 & 55,3926 & 86,1345 & 120,9956 & 237,2502 \\
\hline & DTM & 35,1358 & 49,3480 & 78,9568 & 111,0330 & 219,5987 & 40,7500 & 62,0544 & 94,5853 & 146,2677 & 261,1053 & 37,8317 & 55,3926 & 86,1345 & 120,9956 & 237,2502 \\
\hline & Leissa & 41,0576 & 57,0244 & 98,6960 & 128,3049 & 256,6097 & 41,3782 & 62,3131 & 102,2162 & 170,1112 & 342,1442 & 41,2070 & 59,4627 & 100,2698 & 147,6353 & 320,7921 \\
\hline & DQM & 41,0576 & 57,0244 & 98,6960 & 128,3049 & 256,6097 & 41,3782 & 62,3131 & 102,2162 & 170,1112 & 342,1470 & 41,2070 & 59,4627 & 100,2698 & 147,6353 & 320,7921 \\
\hline 5 & FDM & 40,9714 & 56,9011 & 98,2593 & 128,0276 & 256,0712 & 41,3782 & 62,3131 & 102,2162 & 170,1112 & 342,1456 & 41,2070 & 59,4627 & 100,2698 & 147,6353 & 320,7921 \\
\hline & DTM & 41,0576 & 57,0244 & 98,6960 & 128,3049 & 256,6097 & 41,3782 & 62,3131 & 102,2162 & 170,1112 & 342,1442 & 41,2070 & 59,4627 & 100,2698 & 147,6353 & 320,7921 \\
\hline & Leissa & 45,7950 & 78,9568 & 98,6960 & 177,6529 & 286,2185 & 47,0009 & 88,8047 & 129,0955 & 189,1219 & 392,8746 & 46,3620 & 83,6060 & 113,2281 & 184,1006 & 322,9642 \\
\hline & DQM & 45,7950 & 78,9568 & 98,6960 & 177,6529 & 286,2185 & 47,0009 & 88,8047 & 129,0955 & 189,1219 & 392,8746 & 46,3620 & 83,6060 & 113,2281 & 184,1006 & 322,9672 \\
\hline $6^{10}$ & FDM & 45,6960 & 78,6798 & 98,2593 & 177,0295 & 285,6000 & 47,0009 & 88,8047 & 129,0955 & 189,1219 & 392,8746 & 46,3620 & 83,6060 & 113,2281 & 184,1006 & 322,9657 \\
\hline & DTM & 45,7950 & 78,9568 & 98,6960 & 177,6529 & 286,2185 & 47,0009 & 88,8047 & 129,0955 & 189,1219 & 392,8746 & 46,3620 & 83,6060 & 113,2281 & 184,1006 & 322,9642 \\
\hline & Leissa & 49,3480 & 80,0535 & 128,3049 & 180,1203 & 308,4251 & 56,1782 & 94,2131 & 140,2045 & 212,8169 & 415,6906 & 52,9007 & 88,4384 & 133,7910 & 193,8025 & 346,7382 \\
\hline $7^{\text {th }}$ & DQM & 49,3485 & 80,0534 & 128,3049 & 180,1203 & 308,4283 & 56,1782 & 94,2131 & 140,2045 & 212,8169 & 415,6906 & 52,9014 & 88,4384 & 133,7910 & 193,8025 & 346,7382 \\
\hline 7 & FDM & 48,8119 & 79,4430 & 127,7881 & 178,7467 & 305,0742 & 56,1782 & 94,2131 & 140,2045 & 212,8169 & 415,6906 & 52,9010 & 88,4384 & 133,7910 & 193,8025 & 346,7382 \\
\hline & DTM & 49,3480 & 80,0535 & 128,3049 & 180,1203 & 308,4251 & 56,1782 & 94,2131 & 140,2045 & 212,8169 & 415,6906 & 52,9007 & 88,4384 & 133,7910 & 193,8025 & 346,7382 \\
\hline & Leissa & 53,6906 & 93,2129 & 128,3049 & 209,7291 & 335,5665 & 56,6756 & 97,4254 & 154,7757 & 276,0012 & 444,9682 & 54,8720 & 93,6758 & 140,8456 & 243,4964 & 391,0659 \\
\hline $8^{\text {th }}$ & DQM & 53,6906 & 93,2129 & 128,3049 & 209,7291 & 335,5665 & 56,6758 & 97,4254 & 154,7757 & 276,0047 & 445,0107 & 54,8720 & 93,6758 & 140,8456 & 243,4964 & 391,0659 \\
\hline 8 & FDM & 53,5363 & 92,7791 & 127,7881 & 208,7530 & 334,6019 & 56,6757 & 97,4254 & 154,7757 & 276,0030 & 444,9894 & 54,8720 & 93,6758 & 140,8456 & 243,4964 & 391,0659 \\
\hline & DTM & 53,6906 & 93,2129 & 128,3049 & 209,7291 & 335,5665 & 56,6756 & 97,4254 & 154,7757 & 276,0012 & 444,9682 & 54,8720 & 93,6758 & 140,8456 & 243,4964 & 391,0659 \\
\hline
\end{tabular}


Table 11. Nondimensional natural frequencies of the plate elements for different boundary cases and aspect ratios (cont')

\begin{tabular}{|c|c|c|c|c|c|c|c|c|c|c|c|c|c|c|c|c|}
\hline \multirow{3}{*}{\multicolumn{2}{|c|}{$\begin{array}{c}\text { Boundary } \\
\text { Conditions } \\
\text { Aspect Ratio }\end{array}$}} & \multicolumn{5}{|c|}{ S-C-S-F } & \multicolumn{5}{|c|}{ S-S-S-F } & \multicolumn{5}{|c|}{ S-F-S-F } \\
\hline & & \multicolumn{5}{|c|}{$\mathbf{a} / \mathbf{b}$} & \multicolumn{5}{|c|}{$\mathbf{a} / \mathbf{b}$} & \multicolumn{5}{|c|}{$\mathbf{a} / \mathbf{b}$} \\
\hline & & $2 / 5$ & $2 / 3$ & 1.0 & $3 / 2$ & $5 / 2$ & $2 / 5$ & $2 / 3$ & 1.0 & $3 / 2$ & $5 / 2$ & $2 / 5$ & $2 / 3$ & 1.0 & $3 / 2$ & $5 / 2$ \\
\hline \multirow{4}{*}{$1^{\text {st }}$} & Leissa & 10,1888 & 10,9752 & 12,6874 & 16,8225 & 30,6277 & 10,1259 & 10,6712 & 11,6845 & 13,7111 & 18,8009 & 9,7600 & 9,6983 & 9,6314 & 9,5582 & 9,4841 \\
\hline & DQM & 10,1485 & 10,9011 & 12,5569 & 16,6003 & 30,2740 & 10,0889 & 10,6083 & 11,5816 & 13,5359 & 18,4640 & 9,7280 & 9,6507 & 9,5676 & 9,4777 & 9,3879 \\
\hline & FDM & 10,1686 & 10,9381 & 12,6221 & 16,7114 & 30,4508 & 9,7277 & 10,0728 & 11,8270 & 23,9206 & 63,5380 & 9,8829 & 9,9988 & 10,2012 & 10,4804 & 10,1883 \\
\hline & DTM & 10,1888 & 10,9752 & 12,6874 & 16,8225 & 30,6277 & 10,1259 & 10,6712 & 11,6845 & 13,7111 & 18,8009 & 10,0378 & 10,3469 & 10,8348 & 11,4830 & 10,9887 \\
\hline \multirow{4}{*}{$2^{\text {nd }}$} & Leissa & 13,6036 & 20,3355 & 33,0651 & 45,3024 & 58,0804 & 13,0570 & 18,2995 & 27,7563 & 43,5723 & 50,5405 & 11,0368 & 12,9813 & 16,1348 & 21,6192 & 33,6228 \\
\hline & DQM & 13,5500 & 20,2229 & 32,8924 & 44,9543 & 57,3722 & 13,0087 & 18,1977 & 27,5917 & 43,2840 & 49,9897 & 10,9589 & 12,8314 & 15,8799 & 21,2000 & 32,8788 \\
\hline & FDM & 13,5768 & 20,2792 & 32,9788 & 45,1284 & 57,7263 & 12,0663 & 17,0357 & 28,1930 & 56,2547 & 92,0352 & 10,7866 & 12,4334 & 15,2098 & 20,3168 & 32,6301 \\
\hline & DTM & 13,6036 & 20,3355 & 33,0651 & 45,3024 & 58,0804 & 13,0570 & 18,2995 & 27,7563 & 43,5723 & 50,5405 & 10,6142 & 12,0355 & 14,5397 & 19,4336 & 32,3814 \\
\hline \multirow{4}{*}{$3^{\text {rd }}$} & Leissa & 20,0971 & 37,9552 & 41,7019 & 61,0178 & 105,5470 & 18,8390 & 33,6974 & 41,1967 & 47,8571 & 100,2321 & 15,0626 & 22,9535 & 36,7256 & 38,7214 & 38,3629 \\
\hline & DQM & 20,0296 & 37,8421 & 41,4952 & 60,7948 & 104,6398 & 18,7755 & 33,5854 & 41,0126 & 47,6284 & 99,4954 & 14,9557 & 22,7458 & 36,4173 & 38,5132 & 38,0701 \\
\hline & FDM & 20,0634 & 37,8987 & 41,5986 & 60,9063 & 105,0934 & 17,4793 & 32,3386 & 41,6736 & 79,3076 & 124,4366 & 15,1461 & 23,1100 & 36,9313 & 40,1830 & 41,4213 \\
\hline & DTM & 20,0971 & 37,9552 & 41,7019 & 61,0178 & 105,5470 & 18,8390 & 33,6974 & 41,1967 & 47,8571 & 100,2321 & 15,3365 & 23,4742 & 37,4453 & 41,8528 & 44,7725 \\
\hline \multirow{4}{*}{$4^{\text {th }}$} & Leissa & 29,6219 & 40,2717 & 63,0148 & 92,3073 & 149,4569 & 27,5580 & 40,1307 & 59,0655 & 81,4789 & 110,2259 & 21,7064 & 39,1052 & 38,9450 & 54,8443 & 75,2037 \\
\hline & DQM & 29,5515 & 40,1378 & 62,7128 & 91,7877 & 149,1969 & 27,4891 & 40,0055 & 58,7953 & 81,0037 & 109,9391 & 21,5778 & 38,9939 & 38,7925 & 54,1434 & 73,8562 \\
\hline & FDM & 29,5867 & 40,2047 & 62,8638 & 92,0475 & 149,3269 & 26,0747 & 38,9956 & 59,8569 & 107,4724 & 132,8902 & 21,5319 & 39,4607 & 39,6754 & 52,2596 & 70,5994 \\
\hline & DTM & 29,6219 & 40,2717 & 63,0148 & 92,3073 & 149,4569 & 27,5580 & 40,1307 & 59,0655 & 81,4789 & 110,2259 & 21,4860 & 39,9276 & 40,5583 & 50,3758 & 67,3425 \\
\hline \multirow{4}{*}{$5^{\text {th }}$} & Leissa & 39,6382 & 49,7317 & 72,3976 & 93,8293 & 173,1060 & 39,3377 & 48,4082 & 61,8606 & 92,6925 & 147,6317 & 31,1771 & 40,3560 & 46,7381 & 65,7922 & 86,9684 \\
\hline & DQM & 39,5521 & 49,5704 & 72,2579 & 93,3642 & 172,0157 & 39,2712 & 48,2611 & 61,7156 & 92,2784 & 146,8273 & 31,0433 & 40,1448 & 46,3264 & 65,3906 & 86,4624 \\
\hline & FDM & 39,5952 & 49,6511 & 72,3278 & 93,5968 & 172,5608 & 37,7263 & 46,7280 & 62,8647 & 118,6069 & 174,0607 & 31,1908 & 40,0804 & 45,3157 & 65,9847 & 90,8630 \\
\hline & DTM & 39,6382 & 49,7317 & 72,3976 & 93,8293 & 173,1060 & 39,3377 & 48,4082 & 61,8606 & 92,6925 & 147,6317 & 31,3384 & 40,0161 & 44,3050 & 66,5788 & 95,2636 \\
\hline \multirow{4}{*}{$6^{\text {th }}$} & Leissa & 42,2425 & 64,1889 & 90,6114 & 141,7834 & 182,8110 & 39,6118 & 57,5929 & 90,2941 & 124,5635 & 169,1026 & 39,2387 & 42,6847 & 70,7401 & 87,6262 & 130,3576 \\
\hline & DQM & 42,1763 & 64,0914 & 90,3100 & 141,1038 & 182,0009 & 39,5285 & 57,4931 & 90,0123 & 124,3978 & 168,1679 & 39,1623 & 42,4333 & 70,1583 & 87,2832 & 128,5459 \\
\hline & FDM & 42,2094 & 64,1402 & 90,4607 & 141,4436 & 182,4059 & 38,5982 & 56,2897 & 91,2438 & 173,1190 & 207,0340 & 39,3938 & 41,9350 & 71,1953 & 89,2697 & 123,6711 \\
\hline & DTM & 42,2425 & 64,1889 & 90,6114 & 141,7834 & 182,8110 & 39,6118 & 57,5929 & 90,2941 & 124,5635 & 169,1026 & 39,6252 & 41,4367 & 72,2323 & 91,2562 & 118,7962 \\
\hline \multirow{4}{*}{$7^{\text {th }}$} & Leissa & 42,9993 & 67,8993 & 103,1617 & 149,6055 & 235,0155 & 42,6964 & 64,7281 & 94,4837 & 132,8974 & 203,7304 & 40,5035 & 54,2400 & 75,2834 & 103,9665 & 155,3211 \\
\hline & DQM & 42,9233 & 67,6895 & 102,8104 & 149,4512 & 233,7042 & 42,6245 & 64,5319 & 94,1471 & 132,2895 & 202,5149 & 40,3561 & 53,9117 & 75,0180 & 103,0219 & 154,5960 \\
\hline & FDM & 42,9613 & 67,7944 & 102,9860 & 149,5284 & 234,3599 & 41,5187 & 62,2175 & 95,9204 & 177,4279 & 240,7948 & 40,1528 & 54,4897 & 74,9561 & 101,3541 & 155,5274 \\
\hline & DTM & 42,9993 & 67,8993 & 103,1617 & 149,6055 & 235,0155 & 42,6964 & 64,7281 & 94,4837 & 132,8974 & 203,7304 & 39,9495 & 55,0678 & 74,8941 & 99,6863 & 156,4589 \\
\hline \multirow{4}{*}{$8^{\text {th }}$} & Leissa & 49,5740 & 89,3571 & 111,8964 & 162,2413 & 260,6371 & 48,7745 & 89,1859 & 108,9185 & 158,9180 & 257,4791 & 43,6698 & 66,2301 & 87,9867 & 105,1608 & 156,1248 \\
\hline & DQM & 49,4798 & 89,1464 & 111,5334 & 161,6387 & 259,3490 & 48,6852 & 88,9607 & 108,5875 & 158,4272 & 256,3328 & 43,5425 & 66,0428 & 87,7363 & 104,2345 & 155,6431 \\
\hline & FDM & 49,5269 & 89,2518 & 111,7149 & 161,9400 & 259,9930 & 46,8259 & 86,1713 & 110,1721 & 195,0900 & 283,7807 & 43,5460 & 66,2422 & 88,7866 & 105,2666 & 160,1529 \\
\hline & DTM & 49,5740 & 89,3571 & 111,8964 & 162,2413 & 260,6371 & 48,7745 & 89,1859 & 108,9185 & 158,9180 & 257,4791 & 43,5495 & 66,4417 & 89,8370 & 106,2987 & 164,6628 \\
\hline
\end{tabular}



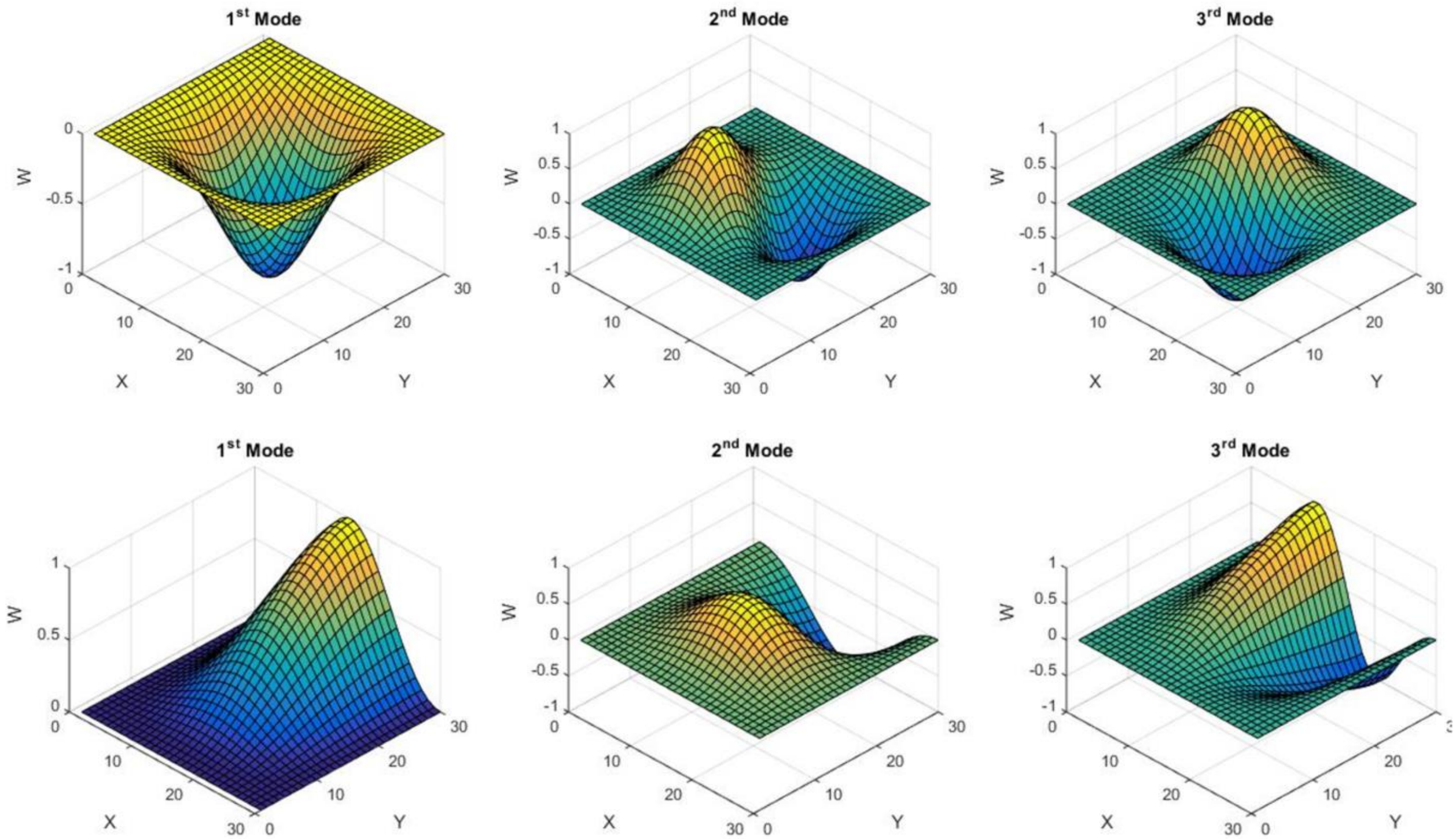

Figure 6. Mode shapes of the plate elements for SSSS and SSSF boundary conditions 

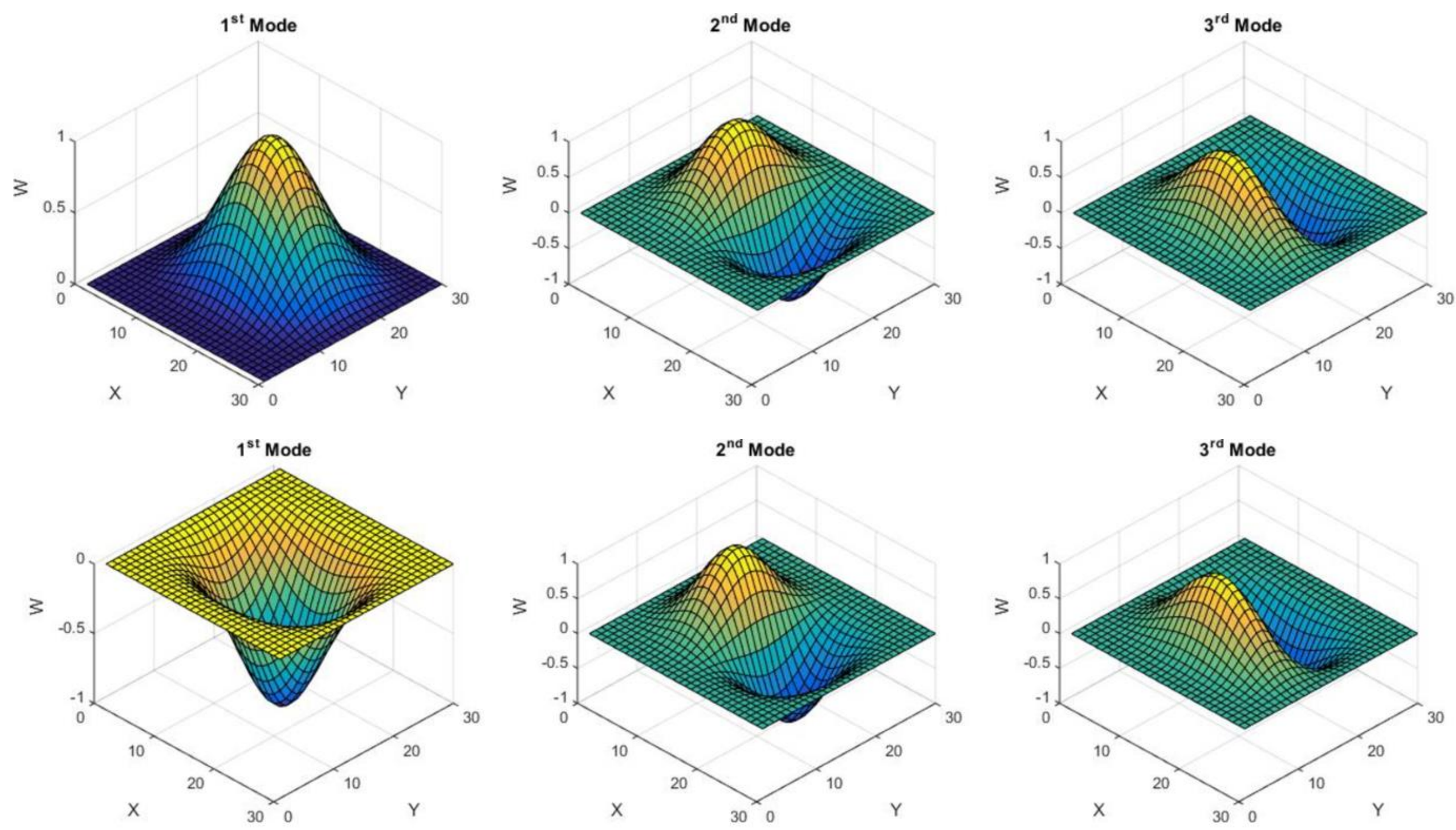

Figure 6. Mode shapes of the plate elements for SCSS and SCSC boundary conditions (cont') 

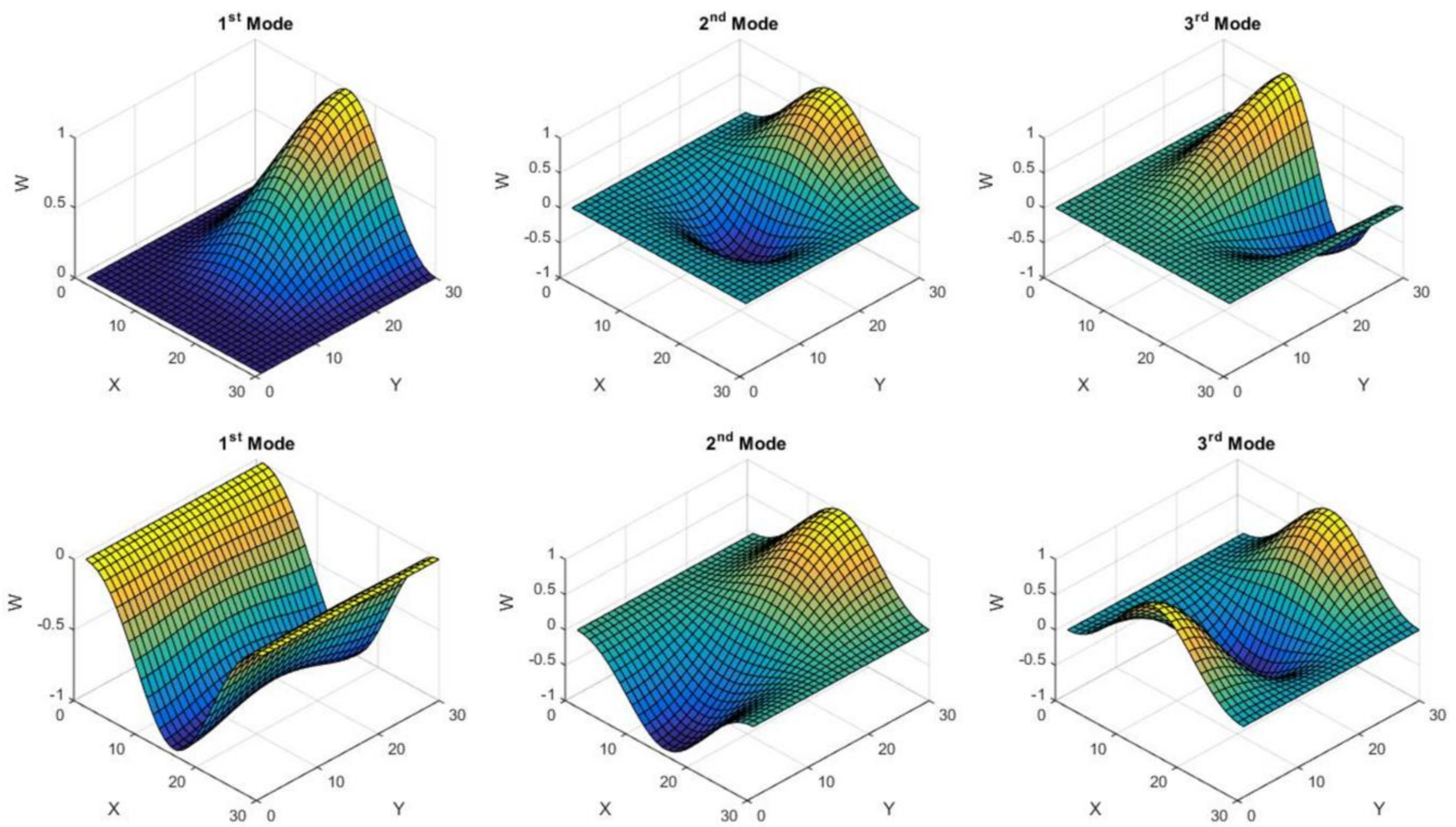

Figure 6. Mode shapes of the plate elements for SCSF and SFSF boundary conditions (cont') 


\section{Conclusion}

This paper has computed the dynamic characteristics of the Euler-Bernoulli beam and Kirchhoff-Love plate by employing different numerical methods. Of these methods, DTM converges to analytical results faster than the other two methods for simplysupported boundary conditions. Also, it can be seen from Tables 10 and 11 that absolute error is smaller than other methods. On the other hand, the term size of DQM is smaller than FDM (see Figure 4), so it converges faster than FDM. In other words, it is computationally more efficient due to its small term size and requires less computer memory than FDM. As a result, DTM can be preferred for any type of one-dimensional differential equation. On the other hand, DQM can be preferred for multi-dimensional engineering problems, complicated geometries.

\section{Acknowledgements}

The authors would like to thank Prof. Dr. Guven Komurgoz from the Department of Electrical Engineering in Istanbul Technical University for suggestions and discussions, and would also like to thank Res. Asst. Ahmet Gokay Ozturk from the Department of Aeronautical Engineering in Istanbul Technical University for endless help during the preparation of this study.

\section{References}

Bellman, R., Kashef, B.G., Casti, J. (1972). Differential quadrature: a technique for the rapid solution of nonlinear partial differential equations. Journal of Computational Physics, 10, 40-52.

Civan, F., Sliepcevich, C.M. ( 1984). Differential Quadrature for Multidimensional Problems. Journal of Mathematical Analysis and Applications, 101, 423-443.

Wang, X., Bert, W. (1993). A new approach in Applying Differential Quadrature to Static and Free Vibrational Analyses of Beams and Plates. Journals of Sound and Vibration, 162, 566-572.

Wang, X., Bert, C.W., Striz, A.G. ( 1993). Differential Quadrature Analysis of Deflection, Buckling, and Free Vibration of Beams and Rectangular Plates. Computers and Structures, 48, 473-479.

Du, H., Lim, M. K., Lin, R. M. (1994). Application of Generalized Differential Quadrature Method to Structural Problems. International Journal of Numerical Methods in Engineering, 37, 1881-1896.

Du, H., Lim, M. K., Lin, R. M. (1995). Application of Differential Quadrature to Vibration Analysis. Journal of Sound and Vibration, 181, 279-293.

Malik, M., Bert, C. W. (1996). Implementing Multiple Boundary Conditions in the DQ Solution of Higher Order PDEs: Application to Free Vibration of Plates. International Journal for Numerical Methods in Engineering, 39, 1237-1258.

Bert, C.W., Malik, M. (1996). Semianalytical Differential Quadrature Solution for Free Vibration Analysis of Rectangular Plates. AIAA Journal, 34(3), 601-606.

Shu, C., Du, H. (1997). Implementation of Clamped and Simply Supported Boundary Conditions in The GDQ Free Vibration Analysis of Beams and Plates. International Journal of Solid Structures, 34(7), 819-835.
Tornabene, F., Viola, E., Inman, D. J. (, 2009). 2-D differential quadrature solution for vibration analysis of functionally graded conical, cylindrical shell and annular plate structures. Journal of Sound and Vibration, 328 (3), 259-290.

Arikoglu, A., Ozkol, I. (2012). Vibration Analysis of Composite Sandwich Plates by the Generalized Differential Quadrature Method. AIAA Journal, 50 (3), 620-630.

Tornabene, F., Fantuzzi, N., Bacciocchi, M., Dimitri, R. (2015). Free vibrations of composite oval and elliptic cylinders by the generalized differential quadrature method. Thin Walled Structures, 97, 114-129.

Yavuz, M. T., Ozkol, I. (2021). Free Vibration Analysis of a Rotating Double Tapered Beam with Flexible Root via Differential Quadrature Method. Aircraft Engineering and Aerospace Technology, 93( 5), 900-914.

Zhou, J. K. (1986). Differential Transformation and Its Application for Electrical Circuits. Huazhong University Press, Wuhan, China.

Malik, M., Dang, H. H. (1998). Vibration Analysis of Continuous Systems by Differential Transformation. Applied Mathematics and Computation, 96, 17-26.

Malik, M., Allali., M. (2000). Characteristic Equations of Rectangular Plates by Differential Transformation. Journal of Sound and Vibration, 233(2), 359-366.

Chen, C. K., Ho, S. H. ( 1996). Application of Differential Transformation Method to Eigenvalue Problems. Applied Mathematics and Computation, 79, 173-188.

Chen, C. K., Ho, S. H. (1999). Solving Partial Differential Equations by Two Dimensional Differential Transform Method. Applied Mathematics and Computation, 106, 171179.

Yeh, Y. L., Jang, M. J., Wang, C. C. (2006). Analyzing the free vibrations of a plate using finite difference and differential Transformation Method. Applied Mathematics and Computation, 178, 493-501.

Yalcin, S., Arikoglu, A., Ozkol, I. (2009).Free Vibration Analysis of Circular Plates by Differential Transformation Method. Applied Mathematics and Computation, 212, 377-386.

Jang, M. J., Chen, C. L., Liu, Y. C. (2001). Two-dimensional Differential Transform for Partial Differential Equations. Applied Mathematics and Computation, 123, 109-122.

Arikoglu, A., Ozkol, I. (2010). Vibration analysis of composite sandwich beams with viscoelastic core by using differential transform method. Composite Structures, 92 (12), 3031-2039.

Shu, C. (2000). Differential Quadrature and Its Application in Engineering. Springer.

Hatami, M., Ganji, D. D., Sheikholesmani, M. (2017). Differential Transformation Method for Mechanical Engineering Problems. Academic Press.

Blevins, R. D. (2001). Formulas for natural frequency and mode shape. Krieger Publishing.

Leissa, A.W. (1973). The Free Vibration of Rectangular Plates. Journal of Sound and Vibration, 31(3), 257-293. 